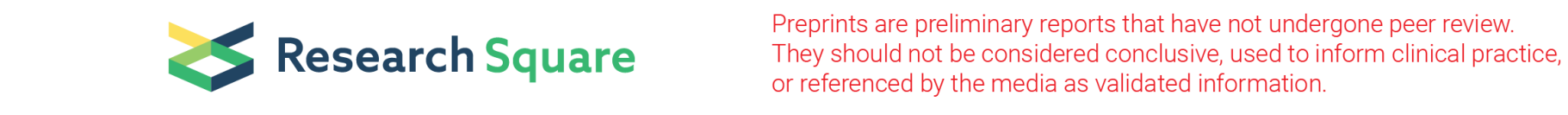

\title{
Production and Optimization of GLP-HDPE Composite Materials Using the Robust Taguchi Technique
}

\author{
Sunday JATAU \\ Danjuma Saleh Yawas \\ Laminu Shettima Kuburi \\ Bassey Okon Samuel ( $\sim$ basseyokon59@gmail.com ) \\ Ahmadu Bello University https://orcid.org/0000-0001-9104-7063
}

\section{Research Article}

Keywords: Optimization, Modelling, ANOVA, Composite, Modulus, HDPE

Posted Date: February 10th, 2022

DOl: https://doi.org/10.21203/rs.3.rs-1330643/v1

License: (9) (1) This work is licensed under a Creative Commons Attribution 4.0 International License. Read Full License 


\section{Abstract}

With the increase in the use of high-density polyethylene (HDPE) products and the serious long-term hazard it poses to the environment, there has been an increasing need to decrease the release of these materials to the environment as waste. This study sets out to develop and optimize the mechanical properties of GLP-HDPE composite, a sustainable material from agro residues (ginger leaves particles (GLP)) and high-density polyethylene waste materials. The Taguchi robust technique, analysis of variance, and regression analysis were employed to optimize, analyze and model the behavior of the composite materials in respect to developmental factors of particle size and particle content. The optimum bending modulus of elasticity (MOE), modulus of rupture (MOR) and impact energy (IE) of the developed composites was 2490MPa, $11.90 \mathrm{MPa}$, and $4.1 \mathrm{~J}$ at particle size/particle content combination of $710 \mu \mathrm{m} / 35 \%, 520 \mu \mathrm{m} / 35 \%$, and $710 \mu \mathrm{m} / 45 \%$ respectively. Analysis of variance at $95 \%$ confidence level showed that the particle content and a significant effect on the MOE, MOR, and IE of the GLP-HDPE composite with a minimum percentage contribution of $71.61 \%$. Equations for predicting the MOE, MOR, and IE of the composites were developed with good prediction accuracy.

\subsection{Introduction}

Recently, the major focus on materials research has been the conversion of waste materials to reusable products. That is, converting waste to wealth, an idea of the "circular economy" (Sidkar et al., 2020; Jain et al., 2022). HDPE is a popular material used in everyday activities like food and goods packaging, furniture making, etc. Most of these are usually incinerated when out of use and due to their low degradability, lead to a large accumulation of it, posing health risks to humans and ecological hazards to the water bodies (Hariharan et al., 2021). The possibility of recycling these waste products may not only be of economic benefit but also great ecological benefit (Gopinath et al., 2020). Also recently, there has been the development of new composite materials with these waste HDPE materials. Although several reports can be found in the literature about the recycling of plastic materials, only a few focus on recovering and molding them in a new process. Laria et al. (2020) analyzed the mechanical properties of a material formed by $100 \%$ recycled plastics: polyethylene terephthalate and low-/high-density polyethylene without previous separation or washing and drying pretreatments. Its macro and microscopic structure were studied and described, and formulations of different compound rates were analyzed. Good mechanical properties obtained reinforce the claims on its ability to be applied for the development of structural components. Also, Koffi et al. (2021) measured the drop weight impact, Izod impact strength, hardness, tensile strength, and elastic modulus of birch-fiber-reinforced HDPE obtained by injection molding. It was observed that the Shore D hardness of virgin HDPE increased by $47.4 \%$ with an increase in fiber content from $0-30 \%$. Also, the improvement of the elastic modulus of the composite with $40 \%$ fiber was $27.2 \%$ superior to a similar material made by compression molding reported earlier. Koffi's study concluded that Birch-fiber-reinforced HDPE could be an adequate alternative to technical polymers widely used in several industrial sectors. Their results show the possibility of converting these waste and hazardous materials into usable products. Although most of these works have used scarce materials like wood particles, foliage plants, etc. which still questions the sustainability of the materials.

A broad spectrum of different biomass waste materials, which are underutilized, bio-renewable, and biodegradable, is produced across the globe in enormous quantities (Mehmood et al., 2021). Since many agro materials are unusable as animal feeds due to their high fiber content or chemical properties, they are usually disposed of (Maraveas et al., 2020). Different studies have been carried out to prove the usability of some of these agro residues in the development of composite materials (Hasanin et al., 2021) just as Nagarajan et al. (2020) utilized agro waste products for structural applications instead of wood. In their work, the a-cellulosic micro filler, which is isolated from Cocos nucifera var Aurantiaca Peduncle (CAP) through the chemical treatment process, is systematically utilized as a reinforcement in thermoset epoxy polymers as a replacement for manmade carbon, ceramic fillers, wood-derived and unsustainable products. The results on mechanical properties such as tensile, flexural, impact test revealed that these properties of the a-cellulosic micro filler reinforced epoxy composites increased in linear nature for $3 \mathrm{wt} \%$ to $15 \mathrm{wt} \%$ of filler loading and $15 \mathrm{wt} \%$ shows the superior behavior in their mechanical properties. This shows that beyond the normal perception of natural fiber reinforced polymer 
composites to have less mechanical properties than their synthetic fiber-reinforced composites, improvements can be made to obtain better performance. And one important factor in the development of good performing materials from agro residue is the careful selection of the reinforcement material.

This implies that beyond the use as foliage for animals, some of these agro residues can be converted to usable materials. Ginger leaves fibers are abundant in many parts of the world and predominantly in the Sahel Savannah regions like Northern Nigeria. Only the root of the crop known as Ginger is used for different purposes such as spicing for food, raw materials for the pharmaceutical industry, etc. but the potential in their highly fibrous leaves has been untapped. In this study composite materials will be developed using particles of the ginger leaves fibers as reinforcement.

Natural fiber-reinforced polymer composites have increasingly been studied. One of the major drawbacks of these fiber composites is their inferior mechanical properties in comparison with synthetic fiber-reinforced polymer composites. Although improvements to these have been made by treating the composites. Studies like Samuel et al. (2021) have proven the possibility of using natural fibers to strengthen and improve the mechanical behavior of polymers when used as reinforcement. This shows that the drawback of lower mechanical properties of the natural fiber reinforced composites can be improved upon.

The Taguchi robust optimization technique is a statistical process of experimental design in which carefully selected variable parameters at different levels combine and the optimum levels of these combinations which produce the best effects are systematically determined. Samuel et al. (2021) applied the Taguchi method in the development of a natural fiber-reinforced polymer material. The approach used brought about an improvement in the tensile property of the material. In the Taguchi approach, the effect (response) is first determined. The variable parameters (control factors) are then carefully selected and an orthogonal array in which the factors interact through their levels is generated. Experimentation is carried out using the combination of the orthogonal array and the results are analyzed. Then a confirmation experiment is carried out to confirm the prediction made during the analysis. The Taguchi experimental design process enables the determination of the optimal process of systems with minimal experimentation to spend resources. In this process, the $\mathrm{S} / \mathrm{N}$ (signal to noise) ratio is used which is a noise absorber (reduced noise). The $\mathrm{S} / \mathrm{N}$ ratio can be referred to as the "higher the better" when the output (response or effect) is expected to be high. E.g. tensile strength, modulus of elasticity, modulus of rupture, impact energy, etc. It is referred to as "nominal the best" when it is expected to be in a range. E.g. body temperature, population growth, etc. The $\mathrm{S} / \mathrm{N}$ ratio is referred to as the "lower the better" when the response is expected to be below. E.g. wear rate, cost, processing time, etc. These S/N ratios can be calculated using Equations 1, 2, and 3 (Yang et al. 1998).

$$
\left(\frac{S}{N}\right)_{H T B}=-10 * \log _{10}\left(\frac{1}{n} \sum_{i=1}^{n} \frac{1}{y_{i}^{2}}\right)
$$

$$
\left(\frac{S}{N}\right)_{N T B}=10 * \log _{10}\left(\frac{1}{n} \sum_{i=1}^{n} \frac{y}{S^{2}}\right)
$$

$$
\left(\frac{S}{N}\right)_{L T B}=-10 * \log _{10}\left(\frac{1}{n} \sum_{i=1}^{n} y_{i}^{2}\right)
$$


Where $\mathrm{n}$ is the number of experiments, $y_{i}$ represents the response value of the $i^{\text {th }}$ an experiment in the orthogonal array, $y$ indicates the mean, and $S^{2}$ the variance of the observed data. Also, $(\mathrm{S} / \mathrm{N})$ represents the Signal to Noise Ratio, and acronyms HTB, NTB, and LTB stand for the Higher the Better, Nominal the Best, and Lower the Better, respectively. Different studies have been carried out in which the Taguchi method was applied in the optimization of different systems or processes (Abifarin, 2021; Samuel et al., 2021).

This study is concerned with developing composites of ginger leaves particle (GLP) reinforced high-density polyethylene (HDPE) polymer composite (GLP-HDPE) and the application of the Taguchi method in the optimization of its mechanical properties. The best composition of the ginger leaves particles content and the particle size which will produce the optimum modulus of elasticity, modulus of rupture, and impact energy will be investigated using this technique. Also, the behavior of the effect of these materials will be modeled and simulated using regression analysis.

\subsection{Experimentation}

\section{Materials}

The ginger leaves were obtained from local ginger farmers in Gidan Mana, Kachia local government area of Kaduna state, Nigeria. The waste high-density polyethylene (HDPE) yogurt bottles were collected directly from the streets of Zaria and around refuse dumps in the school (Ahmadu Bello University Zaria). $\mathrm{NaOH}$ was directly procured from Sigma Aldrich. And distilled water was prepared in the lab.

\section{Preparation}

Treatment of the leaves was carried out according to the methods of Ighalo et al. (2021). The leaves were washed clean with distilled water and soaked in $\mathrm{NaOH}$ for 3 hours for fiber treatment. The treated leaves were removed and dried under atmospheric temperature. The dried leaves were ground and sieved to different particle sizes using sieves of $420 \mu \mathrm{m}$, $520 \mu \mathrm{m}$, and $710 \mu \mathrm{m}$.

The HDPE materials were washed thoroughly and sun-dried. The dried HDPE materials were shredded into pieces and mixing was carried out using two roll mills according to the orthogonal array from the Taguchi design. The roll mixing process was carried out under a temperature of $130^{\circ} \mathrm{C}$. The rolled composites were then transferred to a steel mold which was transferred to the compression machine (Carver-3851) where they were pressed under a pressure of 10MPa at a temperature of $150^{\circ} \mathrm{C}$ for a holding time of 15 mins as in Jaafar et al. (2019).

\section{Characterizations}

\section{Bending modulus of Elasticity (MOE) and Modulus of Rupture (MOR)}

The bending modulus of elasticity (MOE) and modulus of rupture (MOR) of the GLP-HDPE composites was calculated from load-deflection curves according to BS EN 312: 2003. The bending specimens of $50 \mathrm{~mm}$ wide $275 \mathrm{~mm}$ long were cut from each combination of the orthogonal Table. A concentrated bending load was applied at the center with a span of 15 times the thickness of the specimen.

$$
M O R=\frac{3 P_{b} L}{2 b h^{2}}
$$




$$
M O E=\frac{P_{b p} L^{3}}{4 b h^{3} Y_{p}}
$$

Where:

$P_{b}=$ the maximum load $(\mathrm{N}) ; P_{b p}=$ the load at the proportional limit $(\mathrm{N}) ; Y_{p}=$ the deflection corresponding to $P_{b p}(\mathrm{~mm}) ; b=$ the width of the specimen $(\mathrm{mm}) ; h=$ the thickness of the specimen $(\mathrm{mm}) ; L=$ the span $(\mathrm{mm})$.

Impact Energy

The impact test of the composites samples was conducted in the Department of Metallurgical and Materials Engineering, Ahmadu Bello University, Zaria using a fully instrumented Charpy impact testing machine.

A Charpy impact test was conducted on notched samples. Standard square impact test samples measuring $80 \times 10 \times 10 \mathrm{~mm}$ with notch depth of $2 \mathrm{~mm}$ and a notch tip radius of $0.02 \mathrm{~mm}$ at an angle of $45^{\circ}$ was used (ASTM, 2000), and the results were recorded in Joules $(\mathrm{J})$.

\section{Experimental Design}

The mechanical properties optimized include the bending modulus of elasticity, modulus of rupture, and impact energy. The variable parameters which will be considered in the optimization of the GLP-HDPE composites include the ginger leaves particle size and the ginger leaves particle content in weight percent. The variable parameters and their levels considered are presented in Table 1.

Table 1

Variable parameters and the levels

\begin{tabular}{|lllllll|}
\hline S/N & Factor & \multicolumn{3}{l}{ Levels } & & \\
\cline { 3 - 7 } & & $\mathbf{1}$ & $\mathbf{2}$ & $\mathbf{3}$ & $\mathbf{4}$ & $\mathbf{5}$ \\
\hline 1 & Particle Size $(\mu \mathrm{m})(\mathrm{A})$ & 420 & 520 & 710 & & \\
\hline 2 & Particle Content (wt. \%) (B) & 30 & 35 & 40 & 45 & 50 \\
\hline
\end{tabular}

A mixed level design was adopted with the particle size having 3 levels $(420 \mu \mathrm{m}, 520 \mu \mathrm{m}$, and $710 \mu \mathrm{m})$. The particle content in weight percent was considered in 5 levels $(30 \%, 35 \%, 40 \%, 45 \%$, and $50 \%)$. The array for the full combination of the factors and their levels are presented in Table 2. 
Table 2

Orthogonal array for factor and levels combination

\begin{tabular}{|lll|}
\hline SN & GLP Size $(\mu \mathrm{m})$ & GLP Content (wt. \%) \\
\hline 1 & 420 & 30 \\
\hline 2 & 420 & 35 \\
\hline 3 & 420 & 40 \\
\hline 4 & 420 & 45 \\
\hline 5 & 420 & 50 \\
\hline 6 & 520 & 30 \\
\hline 7 & 520 & 35 \\
\hline 8 & 520 & 40 \\
\hline 9 & 520 & 45 \\
\hline 10 & 520 & 50 \\
\hline 11 & 710 & 30 \\
\hline 12 & 710 & 35 \\
\hline 13 & 710 & 40 \\
\hline 14 & 710 & 45 \\
\hline 15 & 710 & 50 \\
\hline
\end{tabular}

Since it was a two-factor mixed-level setting, a full factorial design with 15 different combinations (runs) was obtained. The development of the composite was carried out using the mixed level full factorial orthogonal array presented. The Minitab®19 software will be used for the result analysis.

\subsection{Results And Discussion}

Figure 1 shows the produced ginger leaves particles in different particle sizes.

The mean and $\mathrm{S} / \mathrm{N}$ ratio for bending modulus of elasticity, modulus of rupture, and the impact energy are presented in Table 3. The S/N ratio for the three effects was calculated based on the higher the better criteria represented with Equation 1. 
Table 3

Mean and S/N Ratio of Bending Modulus of Elasticity, Modulus of Rupture, and Impact Energy

\begin{tabular}{|c|c|c|c|c|c|c|c|c|}
\hline \multirow[t]{2}{*}{ SN } & \multirow{2}{*}{$\begin{array}{l}\text { GLP Size } \\
(\mu \mathrm{m})\end{array}$} & \multirow{2}{*}{$\begin{array}{l}\text { GLP Content (wt. } \\
\%)\end{array}$} & \multicolumn{2}{|l|}{ MOE } & \multicolumn{2}{|l|}{ MOR } & \multicolumn{2}{|l|}{ IE } \\
\hline & & & $\begin{array}{l}\text { Mean } \\
(\mathrm{MPa})\end{array}$ & $\begin{array}{l}\mathrm{S} / \mathrm{N} \\
\text { (dB) }\end{array}$ & $\begin{array}{l}\text { Mean } \\
(\mathrm{MPa})\end{array}$ & $S / N(d B)$ & $\begin{array}{l}\text { Mean } \\
(J)\end{array}$ & $\begin{array}{l}S / N \\
\text { (dB) }\end{array}$ \\
\hline 1 & 420 & 30 & 2340 & 67.3843 & 10.51 & 20.4321 & 1.1 & 0.8279 \\
\hline 2 & 420 & 35 & 2450 & 67.7833 & 11.70 & 21.3637 & 1.9 & 5.5751 \\
\hline 3 & 420 & 40 & 2400 & 67.6042 & 11.58 & 21.2742 & 2.8 & 8.9432 \\
\hline 4 & 420 & 45 & 1700 & 64.6090 & 10.05 & 20.0433 & 3.4 & 10.6296 \\
\hline 5 & 420 & 50 & 900 & 59.0849 & 7.37 & 17.3493 & 2.6 & 8.2995 \\
\hline 6 & 520 & 30 & 2370 & 67.4950 & 10.63 & 20.5307 & 1.3 & 2.2789 \\
\hline 7 & 520 & 35 & 2470 & 67.8539 & 11.90 & 21.5109 & 2.2 & 6.8485 \\
\hline 8 & 520 & 40 & 2410 & 67.6403 & 11.62 & 21.3041 & 3.0 & 9.5424 \\
\hline 9 & 520 & 45 & 1950 & 65.8007 & 10.25 & 20.2145 & 3.8 & 11.5957 \\
\hline 10 & 520 & 50 & 950 & 59.5545 & 7.59 & 17.6048 & 2.8 & 8.9432 \\
\hline 11 & 710 & 30 & 2330 & 67.3471 & 10.80 & 20.6685 & 2.0 & 6.0206 \\
\hline 12 & 710 & 35 & 2490 & 67.9240 & 11.65 & 21.3265 & 2.9 & 9.2480 \\
\hline 13 & 710 & 40 & 2400 & 67.6042 & 11.52 & 21.2290 & 3.3 & 10.3703 \\
\hline 14 & 710 & 45 & 2280 & 67.1587 & 9.50 & 19.5545 & 4.1 & 12.2557 \\
\hline \multirow[t]{2}{*}{15} & 710 & 50 & 2100 & 66.4444 & 6.12 & 15.7350 & 3.1 & 9.8272 \\
\hline & & Mean & 2102.67 & 66.0859 & 10.186 & 20.00941 & 2.687 & 8.0804 \\
\hline
\end{tabular}

Where MOE is the bending modulus of elasticity, MOR is the modulus of rupture and IE is the impact energy. The general mean for the MOE, MOR, and IE are $2102.67 \mathrm{MPa}, 10.186 \mathrm{MPa}$, and $2.687 \mathrm{~J}$ respectively and their $\mathrm{S} / \mathrm{N}$ ratios are $66.0859 \mathrm{~dB}$, $20.00941 \mathrm{~dB}$, and $8.0804 \mathrm{~dB}$ respectively. The response table for the means and S/N ratios of the MOE, MOR, and IE are presented in Table 4. Each is derived from averaging the measured responses of the factors at each level. Such that:

$$
S_{P i}=\frac{\sum_{n=1}^{9} \eta_{i n}}{l}
$$

4

Where $S_{P i}$ represents the average response of factor $\mathrm{P}(\mathrm{A}, \mathrm{B})$ at level $\mathrm{i} ; n$ is the experiment number; $\eta_{\text {in }}$ is the result of the $\mathrm{S} / \mathrm{N}$ ratio or mean at level $i$ appearing within the number of runs; $l$ is the number of levels. 
Table 4

Response Table for Means and S/N Ration of MOE, MOR, and IE in Respect to Particle Size and Particle Content.

\begin{tabular}{|c|c|c|c|c|c|c|c|c|c|c|c|c|}
\hline & MOE & & & & MOR & & & & IE & & & \\
\hline \multirow[t]{3}{*}{ Level } & \multirow{2}{*}{\multicolumn{2}{|c|}{$\begin{array}{l}\text { Particle } \\
\text { Size }\end{array}$}} & \multirow{2}{*}{\multicolumn{2}{|c|}{$\begin{array}{l}\text { Particle } \\
\text { Content }\end{array}$}} & \multirow{2}{*}{\multicolumn{2}{|c|}{$\begin{array}{l}\text { Particle } \\
\text { Size }\end{array}$}} & \multirow{2}{*}{\multicolumn{2}{|c|}{$\begin{array}{l}\text { Particle } \\
\text { Content }\end{array}$}} & \multirow{2}{*}{\multicolumn{2}{|c|}{$\begin{array}{l}\text { Particle } \\
\text { Size }\end{array}$}} & \multirow{2}{*}{\multicolumn{2}{|c|}{$\begin{array}{l}\text { Particle } \\
\text { Content }\end{array}$}} \\
\hline & & & & & & & & & & & & \\
\hline & $\begin{array}{l}\text { Mean } \\
\text { (MPa) }\end{array}$ & $\begin{array}{l}S / N \\
\text { (dB) }\end{array}$ & $\begin{array}{l}\text { Mean } \\
\text { (MPa) }\end{array}$ & $\begin{array}{l}S / N \\
\text { (dB) }\end{array}$ & $\begin{array}{l}\text { Mean } \\
\text { (MPa) }\end{array}$ & $\begin{array}{l}S / N \\
\text { (dB) }\end{array}$ & $\begin{array}{l}\text { Mean } \\
\text { (MPa) }\end{array}$ & $\begin{array}{l}S / N \\
\text { (dB) }\end{array}$ & $\begin{array}{l}\text { Mean } \\
\text { (MPa) }\end{array}$ & $\begin{array}{l}S / N \\
\text { (dB) }\end{array}$ & $\begin{array}{l}\text { Mean } \\
(J)\end{array}$ & $\begin{array}{l}S / N \\
\text { (dB) }\end{array}$ \\
\hline 1 & 1958 & 65.29 & 2347 & 67.41 & 10.242 & 20.09 & 10.647 & 20.54 & 2.360 & 6.855 & 1.467 & 3.042 \\
\hline 2 & 2030 & 65.67 & 2470 & 67.85 & 10.398 & 20.23 & 11.750 & 21.40 & 2.620 & 7.842 & 2.333 & 7.224 \\
\hline 3 & 2320 & 67.30 & 2403 & 67.62 & 9.918 & 19.70 & 11.573 & 21.27 & 3.080 & 9.544 & 3.033 & 9.619 \\
\hline 4 & & & 1977 & 65.86 & & & 9.933 & 19.94 & & & 3.767 & 11.494 \\
\hline 5 & & & 1317 & 61.69 & & & 7.027 & 16.90 & & & 2.833 & 9.023 \\
\hline Delta & 362 & 2.00 & 1153 & 6.16 & 0.480 & 0.53 & 4.723 & 4.50 & 0.720 & 2.689 & 2.300 & 8.451 \\
\hline Rank & 2 & 2 & 1 & 1 & 2 & 2 & 1 & 1 & 2 & 2 & 1 & 1 \\
\hline
\end{tabular}

Table 4 shows the MOE, MOR, and IE of the GLP-HDPE composite at different levels of particle size and particle content. The ranking shows that the particle content has more effect on the bending modulus of elasticity, modulus of rupture, and the impact energy as they have the best rank. These effects are depicted graphically in Figures 2, 3, and 4.

Figure 2(A) shows the effect of particle size on the Bending Modulus of Elasticity of the GLP-HDPE composite. There was a constant rise of the bending modulus of elasticity with an increase in particle size. It shows that the highest mean Bending Modulus of Elasticity of $2320 \mathrm{MPa}$ at means and $67.30 \mathrm{~dB}$ at $\mathrm{S} / \mathrm{N}$ ratio on the particle size of $710 \mu \mathrm{m}$ and the lowest Bending Modulus of Elasticity at $420 \mu \mathrm{m}$ particle size. Tensile modulus and internal bonding strength measurements are among the most important indicators of strength in the material and are the most widely specified property (Idris et al., 2011). Tensile modulus is an indication of the relative stiffness of a material; it is a measurement of the property of a material to withstand forces that tend to pull it apart and to determine to what extent the material stretches before breaking. The improvement in tensile modulus was noticed with the developed particleboards. These indicate that the use of ginger leaves particles and RHDPE in the production of the particleboards improved the load-bearing capacity of the board. Increased particle size is indicative of a reduced number of particles, reducing the possibility of fibrillation (initiation of fracture or crack from the interfaces of fiber and matrix adhesion).

The effect of particle content on the Bending Modulus of Elasticity properties is shown in Figure 2(B). It shows an increase in Bending Modulus of Elasticity with the increase in the amount of ginger leaf particle in the composite within a particle content of $30-35 \%$ beyond which there is a drop in the bending modulus of elasticity and the downward trend continues with increasing the particle content of the ginger leaves. The increase in Young's modulus with increasing GLP is expected since the addition of GLP to HDPE increases the stiffness as stated by Bartczak et al. (1999). The presence of a polar group in the HDPE may contribute to electrostatic absorption between HDPE and the agro particles. The reverse trend at $35 \%$ may be attributed to the over-saturation of composite with the GLP leading to particle compaction, and therefore uneven distribution of the particles within the composites. Similar observations have been reported by Adewuyi et al. (2017), Orsar (2004), and Wasylciw (1999). In addition, the developed composite deform less until maximum load, which gives a higher tensile modulus.

Figure 3 (A) shows the effect of particle size on the Modulus of Rupture of the GLP-HDPE composite. There was a constant rise of the Modulus of Rupture with an increase in particle size from $420 \mu \mathrm{m}$ to $520 \mu \mathrm{m}$. Beyond 520 $\mu \mathrm{m}$, the bending 
modulus of rupture reduced. Implying that increasing the particle size of the ginger leaves beyond 520 $\mu \mathrm{m}$ will reduce the Modulus of rupture. It is also observed that the highest mean Modulus of Rupture of $10.398 \mathrm{MPa}$ at means and $20.23 \mathrm{~dB}$ at $\mathrm{S} / \mathrm{N}$ ratio on with particle size of $520 \mu \mathrm{m}$ and lowest Modulus of Rupture at $710 \mu \mathrm{m}$ particle size.

The effect of particle content on the Modulus of Rupture properties is shown in Figure 3 (B). It depicts an increase in Modulus of Rupture with the increase in the amount of ginger leaf particle in the composite within a particle content of 30$35 \%$ beyond which there is a drop in the Modulus of Rupture and the downward trend continues with increasing the particle content of the ginger leaves. This is in agreement with the observation of Rajak et al. (2019).

Figure $4(A)$ shows the effect of particle size on the Impact Energy of the GLP-HDPE composite. There was a linear rise of the Impact Energy with an increase in particle size. It also shows that the highest mean Impact Energy of $3.080 \mathrm{~J}$ at means and $9.544 \mathrm{~dB}$ at $\mathrm{S} / \mathrm{N}$ ratio on the particle size of $710 \mu \mathrm{m}$ and lowest Impact Energy at $420 \mu \mathrm{m}$ particle size. A similar observation was made by Orsar (2014) with the steep increase in the impact strength of the produced GLP-HDPE composite attributed to the presence of particles well bonded by the HDPE binder.

The effect of particle content on the Impact Energy properties is shown in Figure 4 (B). It depicts an increase in Impact Energy with the increase in ginger leaf particles in the composite within a particle content of $30-45 \%$ beyond which there is a drop in the Impact Energy with increasing the particle content of the ginger leaves. The increase in Impact Energy with increasing GLP is expected since the addition of GLP to ginger leaves particles increases the stiffness of the GLP-HDPE composite material. The reverse trend at $45 \%$ particle size may be attributed to the over-saturation of the composite with the GLP leading to particle compaction, increasing the brittleness. Therefore the highest impact energy is obtained at a ginger leaf particle size of $45 \%$ weight content.

Interaction Effects

Interaction effects between the considered factors were studied. The interaction effect is shown in Figure 5 (A-C).

Figure 5 (A) shows the Bending Modulus of Elasticity effect of the interaction between the particle size and the particle content. In agreement with Figure 1(A, B), the highest bending modulus of elasticity is obtained at regions with a combination of low particle content and the content and any particle size. The lowest bending modulus of elasticity was observed at regions of high particle content and low particle sizes. This implies that irrespective of the particle size, to obtain maximum bending modulus, GLP should be kept at lower percentage composition in the composite.

Figure 5 (B) shows the interaction effect between the particle size and the particle content on the Modulus of Rupture. In agreement to Figure 3(A, B), the highest Modulus of Rupture is obtained at regions with a combination of low particle content and the content and any particle size (32-42\%). The lowest Modulus of Rupture was observed at regions of high particle content and low particle sizes. This implies that irrespective of the particle size, to obtain maximum Modulus, GLP should be kept at lower percentage composition in the composite.

Figure $4(C)$ shows the Impact Energy effect of the interaction between the particle size and the particle content. In agreement with Figure 4(A, B), the highest Impact Energy is obtained at regions with a combination of high particle content and larger particle size. The lowest Impact Energy was observed at regions of low particle content and low particle sizes. Also, the reduction in impact energy is observed at particle content greater than $45 \%$. This implies that the best impact energy is obtained at the region of $40-48 \%$ particle content and particle sizes greater than $500 \mu \mathrm{m}$.

Analysis of Variance

The analysis of variance (ANOVA) is used to determine the significance of each factor considered on the effect measured. That is, the ANOVA was used to determine the significance of particle size and particle content on the MOE, MOR, and IE of 
the GLP-HDPE composites. The analysis of variance of means for the MOE, MOR, and IE is presented in Table 5-7 respectively.

Table 5

Analysis of Variance for MOE Means and S/N Ratio

\begin{tabular}{|lcllllllll|}
\hline Source & DF & $\begin{array}{l}\text { SS: } \\
\text { Mean }\end{array}$ & SS: SN & $\begin{array}{l}\text { MS: } \\
\text { Mean }\end{array}$ & $\begin{array}{l}\text { MS: } \\
\text { SN }\end{array}$ & $\begin{array}{l}\text { P: } \\
\text { Mean }\end{array}$ & P: SN & $\begin{array}{l}\text { \% Cont. } \\
\text { Mean (\%) }\end{array}$ & $\begin{array}{l}\% \text { Cont. } \\
\text { S/N (\%) }\end{array}$ \\
\hline Particle Size $(\mu \mathrm{m})(\mathrm{A})$ & 2 & 367213 & 11.33 & 183607 & 5.665 & 0.194 & 0.234 & 9.54 & 9.69 \\
$\begin{array}{l}\text { Particle Content } \\
(\text { wt.\%) (B) }\end{array}$ & 4 & 2755627 & 79.66 & 688907 & 19.915 & 0.008 & 0.015 & 71.61 & 68.15 \\
\hline Residual Error & 8 & 725453 & 25.90 & 90682 & 3.237 & & & 18.85 & 22.16 \\
\hline Total & 14 & 3848293 & 116.89 & & & & & & \\
\hline
\end{tabular}

Table 5 shows the analysis of variance of the Bending modulus of elasticity for the different factors considered. At $95 \%$ confidence interval, the particle size on the $\mathrm{S} / \mathrm{N}$ and mean had an insignificant effect with a P-value of 0.234 and 0.194 $(P>0.005)$. Implying that the particle size has no significant effect on the bending modulus of elasticity. Also, the ginger leaf particles content in the composite showed a significant effect on the Bending Modulus of Elasticity properties of the GLPHDPE composite with a P-value of 0.015 at $\mathrm{S} / \mathrm{N}$ ratio and 0.008 at means which is less than $0.005(\mathrm{P}<0.005)$. The percentage contribution of the particle size and particle content was shown by the analysis of variance of the S/N ratio and Bending Modulus of Elasticity means as depicted in Table 5 to be $9.69 \%, 9.54 \%$, and $68.15 \%, 71.61 \%$ respectively. Implying that the particle content has a higher percentage contribution to the Bending Modulus of Elasticity properties. A change in the particle content has more tendency to affect the Bending Modulus of Elasticity property of the GLP-HDPE Composite.

Table 6

Analysis of Variance for MOR Means and S/N Ratio

\begin{tabular}{|lcllllllll|}
\hline Source & DF & $\begin{array}{l}\text { SS: } \\
\text { Mean }\end{array}$ & SS: SN & $\begin{array}{l}\text { MS: } \\
\text { Mean }\end{array}$ & MS: SN & $\begin{array}{l}\text { P: } \\
\text { Mean }\end{array}$ & P: SN & $\begin{array}{l}\text { \% Cont. } \\
\text { Mean (\%) }\end{array}$ & $\begin{array}{l}\% \text { Cont. } \\
\text { S/N (\%) }\end{array}$ \\
\hline Particle Size $(\mu \mathrm{m})(\mathrm{A})$ & 2 & 0.5995 & 0.7548 & 0.2998 & 0.3774 & 0.162 & 0.211 & 1.32 & 1.76 \\
\hline $\begin{array}{l}\text { Particle Content } \\
\text { (wt.\%) (B) }\end{array}$ & 4 & 43.8847 & 40.5095 & 10.9712 & 10.1274 & 0.000 & 0.000 & 96.39 & 94.54 \\
\hline Residual Error & 8 & 1.0419 & 1.5857 & 0.1302 & 0.1982 & & & 2.29 & 3.70 \\
\hline Total & 14 & 45.5262 & 42.8500 & & & & & & \\
\hline
\end{tabular}

Table 6 shows the analysis of variance of the modulus of rupture concerning the particle size and particle content. At $95 \%$ confidence interval, the particle size on the $\mathrm{S} / \mathrm{N}$ and mean had an insignificant effect with a P-value of 0.211 and 0.162 $(P>0.005)$. Implying that the particle size has no significant effect on the Modulus of Rupture. Also, the ginger leaf particles content in the composite showed a significant effect on the Modulus of Rupture properties of the GLP-HDPE composite with a P-value of 0.000 at $\mathrm{S} / \mathrm{N}$ ratio and 0.000 at means which is less than $0.005(\mathrm{P}<0.005)$. The percentage contribution of the particle size and particle content was shown by the analysis of variance of the $\mathrm{S} / \mathrm{N}$ ratio and Modulus of Rupture means as shown in Table 6 to be 1.76\%, 94.54\%, and 1.32\%, 96.3968\% respectively. Implying that the particle content has a higher percentage contribution to the Modulus of Rupture properties so that a change in the particle content has more tendency to affect the Modulus of Rupture property of the GLP-HDPE Composite. 
Table 7

Analysis of Variance for Impact Energy Means and S/N Ratio

\begin{tabular}{|lccccccccc|}
\hline Source & DF & $\begin{array}{l}\text { SS: } \\
\text { Mean }\end{array}$ & SS: SN & $\begin{array}{l}\text { MS: } \\
\text { Mean }\end{array}$ & MS: SN & $\begin{array}{l}\text { P: } \\
\text { Mean }\end{array}$ & P: SN & $\begin{array}{l}\text { \% Cont. } \\
\text { Mean (\%) }\end{array}$ & $\begin{array}{l}\% \text { Cont. } \\
\text { S/N (\%) }\end{array}$ \\
\hline & 2 & 1.3293 & 18.508 & 0.66467 & 9.2542 & 0.000 & 0.004 & \\
Particle Size $(\mu \mathrm{m})(\mathrm{A})$ & & & & & & & & 12.98 & 12.51 \\
$\begin{array}{l}\text { Particle Content } \\
\text { (wt.\%) (B) }\end{array}$ & 4 & 8.7640 & 123.060 & 2.19100 & 30.7651 & 0.000 & 0.000 & 85.61 & 83.20 \\
\hline Residual Error & 8 & 0.1440 & 6.346 & 0.01800 & 0.7933 & & & 1.41 & 4.29 \\
\hline Total & 14 & 10.2373 & 147.915 & & & & & & \\
\hline
\end{tabular}

Table 7 shows the analysis of variance of the impact energy means and $\mathrm{S} / \mathrm{N}$ ratio in respect to the variable considered. At $95 \%$ confidence interval, the particle size on the S/N and mean had a significant effect with a P-value of 0.004 and 0.000 $(P>0.005)$. Implying that the particle size has a significant effect on the Impact of Energy. Also, the ginger leaf particles content in the composite showed a significant effect on the Impact Energy properties of the GLP/HDPE composite with a Pvalue of 0.000 at $\mathrm{S} / \mathrm{N}$ ratio and 0.000 at means which is less than $0.005(\mathrm{P}<0.005)$. The percentage contribution of the particle size and particle content was shown by the analysis of variance of the $\mathrm{S} / \mathrm{N}$ ratio and Impact Energy means depicted in Table 7 to be of $12.51 \%, 12.98 \%$, and $83.20 \%, 85.61 \%$ respectively. Implying that the particle content has a higher percentage contribution to the Impact Energy properties. A change in the particle content has more tendency to affect the Impact Energy property of the GLP/HDPE Composite.

From Table 4, the optimum levels at which MOE, MOR, and IE are at the maximum are determined from the highest values of means or S/N ratio. The optimum MOE, MOR, and IE of the GLP-HDPE composite material are predicted using Equation 5 .

$$
T_{o p t}=T_{m}+\sum_{k=1}^{k_{n}}\left[\left(T_{i k}\right)_{\text {max }}-T_{m}\right]
$$

5

The optimum of these effects are presented in Table 8 and it is compared with the rest of a confirmation test carried out with the optimum combination.

Table 8

Predicted and Confirmation of the Optimal Properties of the GLP-HDPE polymer composites

\begin{tabular}{|llll|}
\hline & MOE & MOR & IE \\
\hline Optimum Combination & A3B2 & A2B2 & A3B4 \\
\hline Predicted Mean & $2687 \mathrm{~J}$ & $11.962 \mathrm{MPa}$ & $4.16 \mathrm{~J}$ \\
\hline Confirmed Mean & 2490 & $11.90 \mathrm{MPa}$ & $4.1 \mathrm{~J}$ \\
\hline Percentage Error (\%) & 7.33 & 0.52 & 1.4 \\
\hline
\end{tabular}

Regression Analysis 
A mathematical model for the combination of particle size and particle content was derived from regression analysis carried out using the Minitab® 19 statistical software which is used for the prediction of the MOE, MOR, and IE of the developed composite. The regression analysis models are presented in Equations 6-8.

$\mathrm{MOE}=8158-7.30 \mathrm{~A}-169.1 \mathrm{~B}+0.2145 \mathrm{~A} * \mathrm{~B}(6)$

$\mathrm{MOR}=12.28+0.0094 \mathrm{~A}-0.034 \mathrm{~B}-0.000267 \mathrm{~A} * \mathrm{~B}(7)$

Impact Energy $=-3.82+0.00577 \mathrm{~A}+0.1287 \mathrm{~B}-0.000082 \mathrm{~A} * \mathrm{~B}(8)$

The mathematical models have an R-square value of $73.11 \%, 56.55 \%$, and $64.5 \%$ for the MOR, MOR or IE respectively. This is high when compared to the R-Square values of other studies on the modeling of the mechanical properties of fiber reinforced polymer composites.

Figure $6(A, B$, and $C)$ shows the comparison between the predicted and experimental effects.

\subsection{Conclusion}

- Ginger leaves particle reinforced high-density polyethylene (GLP-HDPE) polymer composite was successfully developed.

- Optimization of the modulus of elasticity, modulus of rupture and impact energy of GLP-HDPE composites using the robust Taguchi optimization technique have been reported in this article.

- It is shown that the particle content of ginger leaves fiber is significant in improving the mechanical properties of the material under study. Models for predicting the MOE, MOR, and IE have been developed and reported.

\section{Declarations}

Funding: This research did not receive any funding

Conflicts of interest/Competing interests: On behalf of all authors, the corresponding author states that there is no conflict of interest.

Availability of data and material: Not applicable

Code availability: Not applicable

Ethics approval: Not applicable

Consent to participate: Not applicable

Consent for publication: Not applicable

\section{References}

1. Bartczak, Z., Argon, A. S., Cohen, R. E., \& Weinberg, M. (1999). Toughness mechanism in semi-crystalline polymer blends: II. High-density polyethylene toughened with calcium carbonate filler particles. Polymer, 40(9), 2347-2365.

2. Gopinath, K. P., Nagarajan, V. M., Krishnan, A., \& Malolan, R. (2020). A critical review on energy, environmental and economic factors on various processes used to handle and recycle plastic wastes: development of a comprehensive index. Journal of Cleaner Production, 123031.

3. Hariharan, G., Purvaja, R., Anandavelu, I., Robin, R. S., \& Ramesh, R. (2021). Accumulation and ecotoxicological risk of weathered polyethylene (wPE) microplastics on green mussel (Perna viridis). Ecotoxicology and Environmental Safety, 
208, 111765.

4. Hasanin, M., Shaaban, A. E. A., Essam, M., \& Youssef, A. (2021). Compatibility of Polymer/Fiber to Enhance the Wood Plastic Composite Properties and their Applications. Egyptian Journal of Chemistry, 64(9), 5335-5343.

5. Idris, U. D., Aigbodion, V. S., \& Atuanya, C. U. (2011). Eco-friendly (water melon peels): alternatives to wood-based particleboard composites. Tribology in industry, 33(4), 173.

6. Ighalo, J. O., Adeyanju, C. A., Ogunniyi, S., Adeniyi, A. G., \& Abdulkareem, S. A. (2021). An empirical review of the recent advances in treatment of natural fibers for reinforced plastic composites. Composite Interfaces, 28(9), 925-960.

7. Jaafar, J., Siregar, J. P., Tezara, C., Hamdan, M. H. M., \& Rihayat, T. (2019). A review of important considerations in the compression molding process of short natural fiber composites. The International Journal of Advanced Manufacturing Technology, 105(7), 3437-3450.

8. Jain, A., Sarsaiya, S., Awasthi, M. K., Singh, R., Rajput, R., Mishra, U. C., ... \& Shi, J. (2022). Bioenergy and bio-products from bio-waste and its associated modern circular economy: Current research trends, challenges, and future outlooks. Fuel, 307, 121859.

9. Koffi, A., Koffi, D., \& Toubal, L. (2021). Mechanical properties and drop-weight impact performance of injection-molded HDPE/birch fiber composites. Polymer Testing, 93, 106956.

10. Laria, J. G., Gaggino, R., Kreiker, J., Peisino, L. E., Positieri, M., \& Cappelletti, A. (2020). Mechanical and processing properties of recycled PET and LDPE-HDPE composite materials for building components. Journal of Thermoplastic Composite Materials, 0892705720939141.

11. Maraveas, C. (2020). Production of sustainable and biodegradable polymers from agricultural waste. Polymers, 12(5), 1127.

12. Mehmood, T., Nadeem, F., Qamar, S. A., Bilal, M., \& Iqbal, H. (2021). Bioconversion of agro-industrial waste into valueadded compounds. In Sustainable Bioconversion of Waste to Value Added Products (pp. 349-368). Springer, Cham.

13. Nagarajan, K. J., Balaji, A. N., Basha, K. S., Ramanujam, N. R., \& Kumar, R. A. (2020). Effect of agro waste a-cellulosic micro filler on mechanical and thermal behavior of epoxy composites. International journal of biological macromolecules, 152, 327-339.

14. Rajak, D. K., Pagar, D. D., Menezes, P. L., \& Linul, E. (2019). Fiber-reinforced polymer composites: Manufacturing, properties, and applications. Polymers, 11(10), 1667.

15. Samuel, B.O., Sumaila, M. \& Dan-asabe, B. (2021) Modeling and optimization of the manufacturing parameters of a hybrid fiber reinforced polymer composite PxGyEz. Int J Adv Manuf Technol. https://doi.org/10.1007/s00170-02107930-6

16. Sikdar, S., Siddaiah, A., \& Menezes, P. L. (2020). Conversion of waste plastic to oils for tribological applications. Lubricants, 8(8), 78.

17. Yang, W. H. P., \& Tarng, Y. S. (1998). Design optimization of cutting parameters for turning operations based on the Taguchi method. Journal of materials processing technology, 84(1-3), 122-129.

\section{Figures}



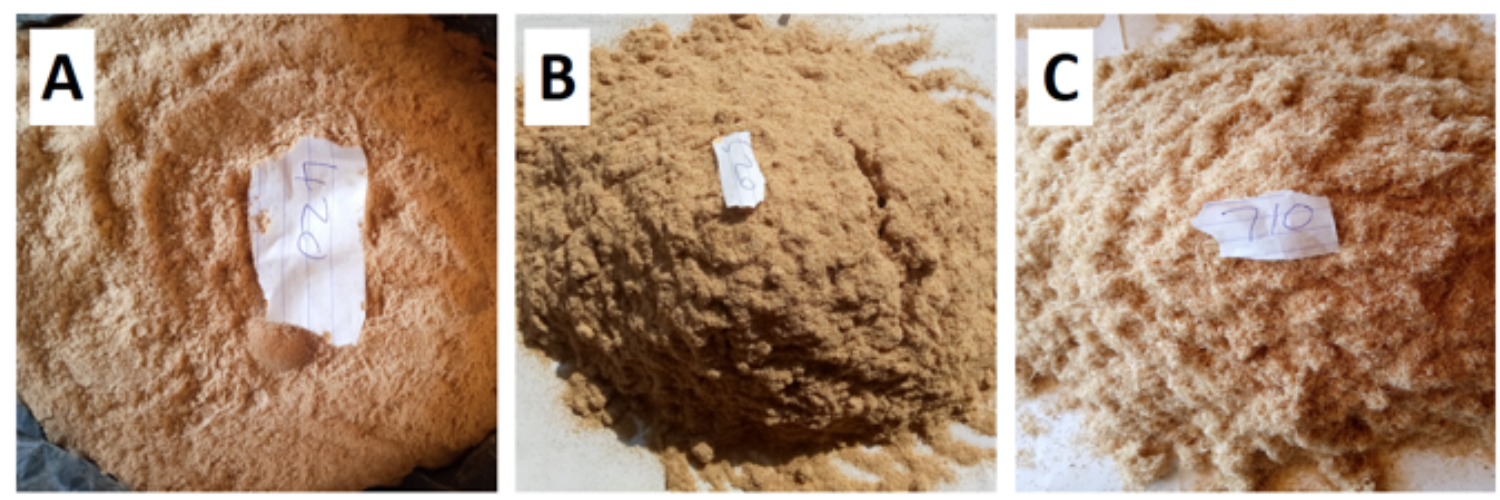

\section{Figure 1}

Produced ginger leaves particles in (a) $420 \mu \mathrm{m}$ (b) $520 \mu \mathrm{m}$ and (c) $710 \mu \mathrm{m}$.

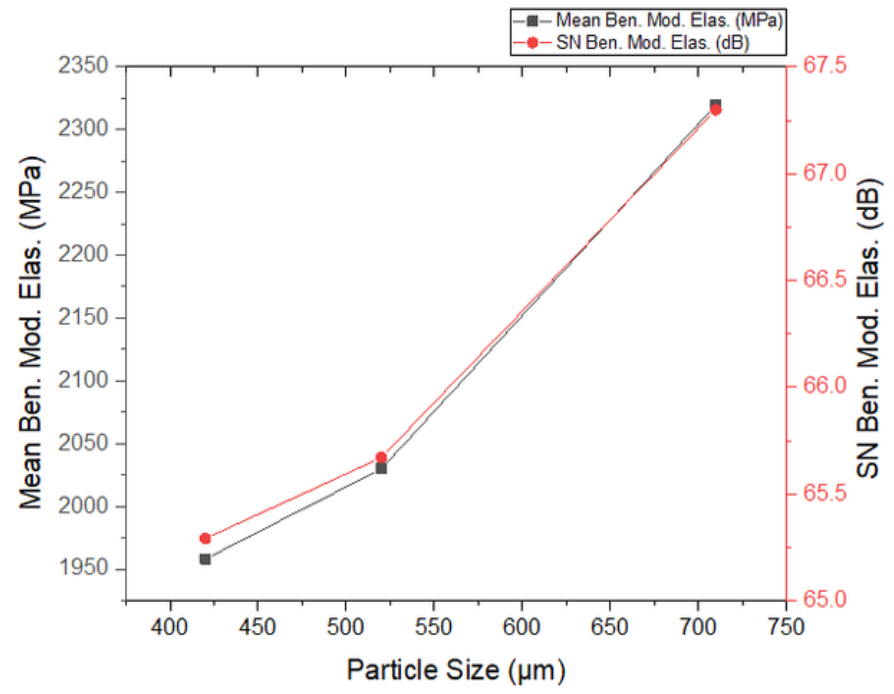

B

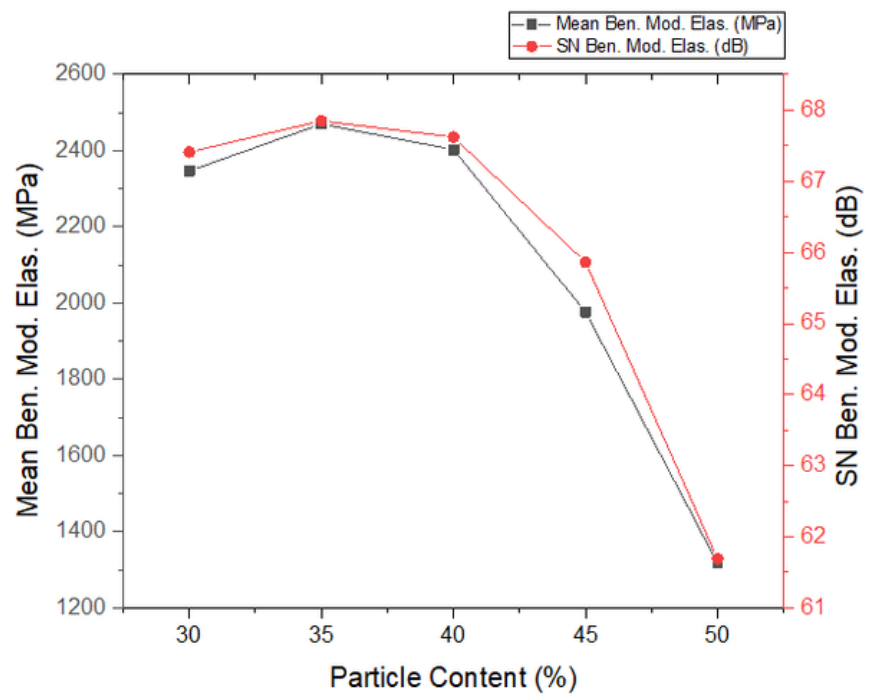




\section{Figure 2}

(A) Variation of Bending Modulus of Elasticity Mean and S/N ratio with Particle Size

(B) Variation of Bending Modulus of Elasticity Mean and S/N ratio with GLP Content.

A

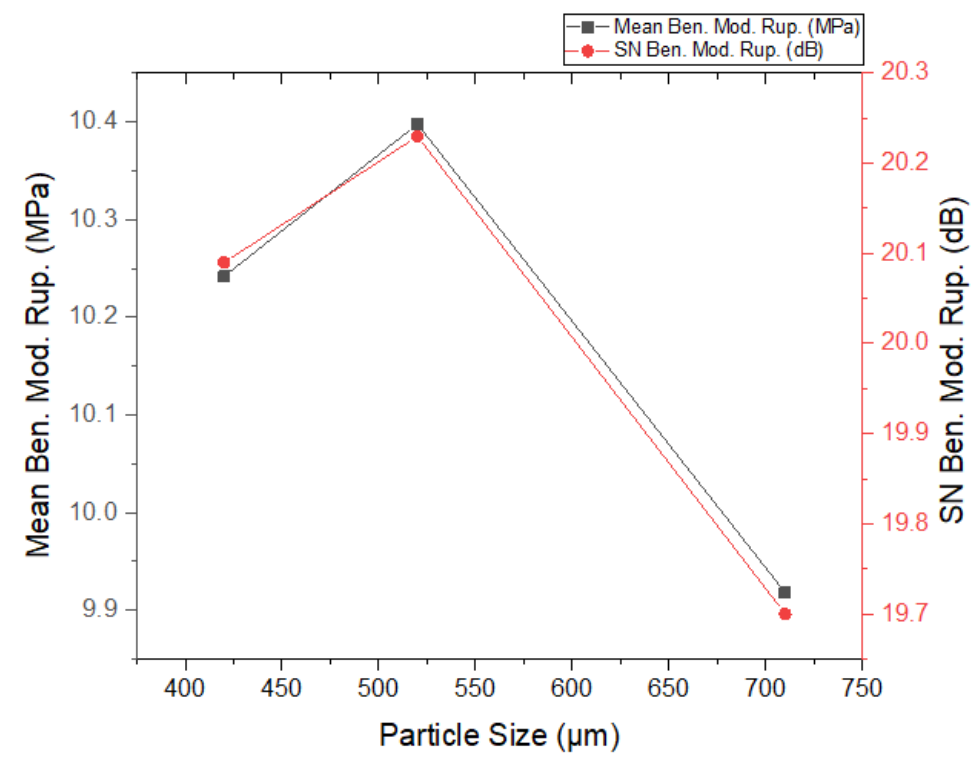

B

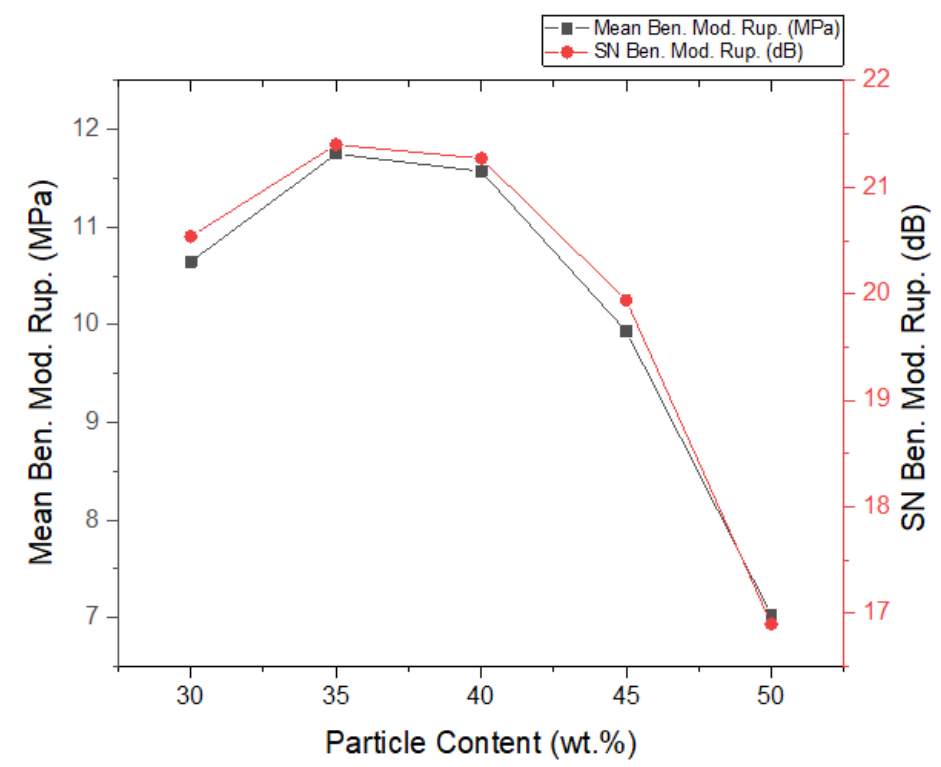

Figure 3

(A) Variation of Modulus of Rupture Mean and S/N ratio with Particle Size

(B) Variation of Modulus of Rupture Mean and S/N ratio with GLP Content 


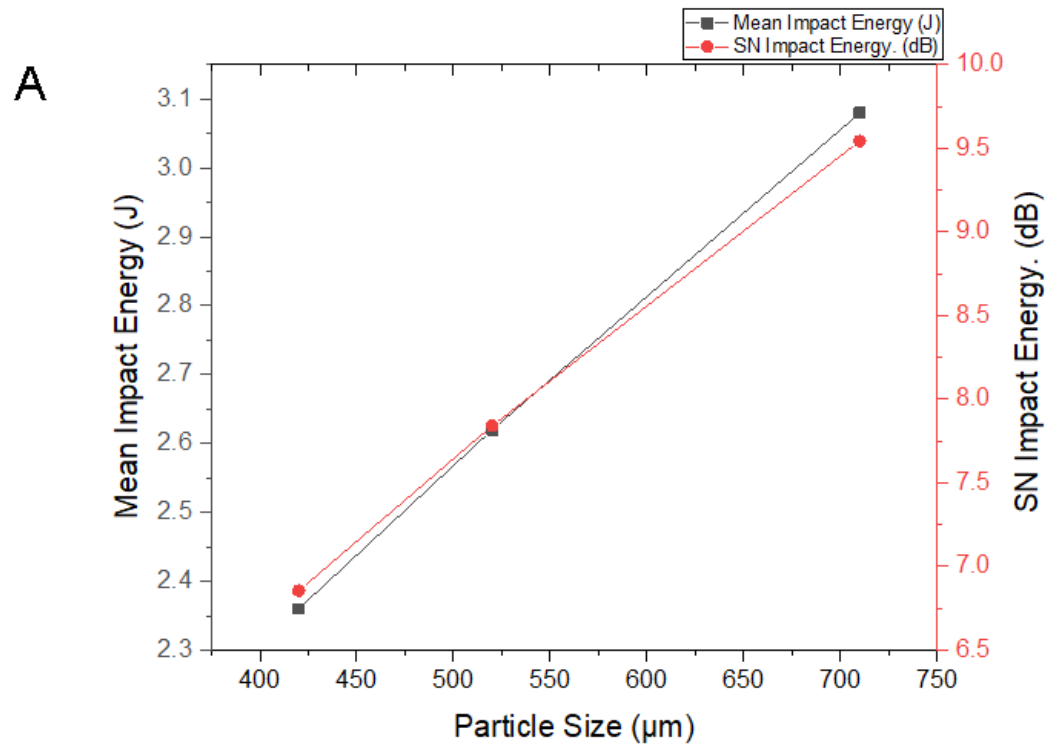

B

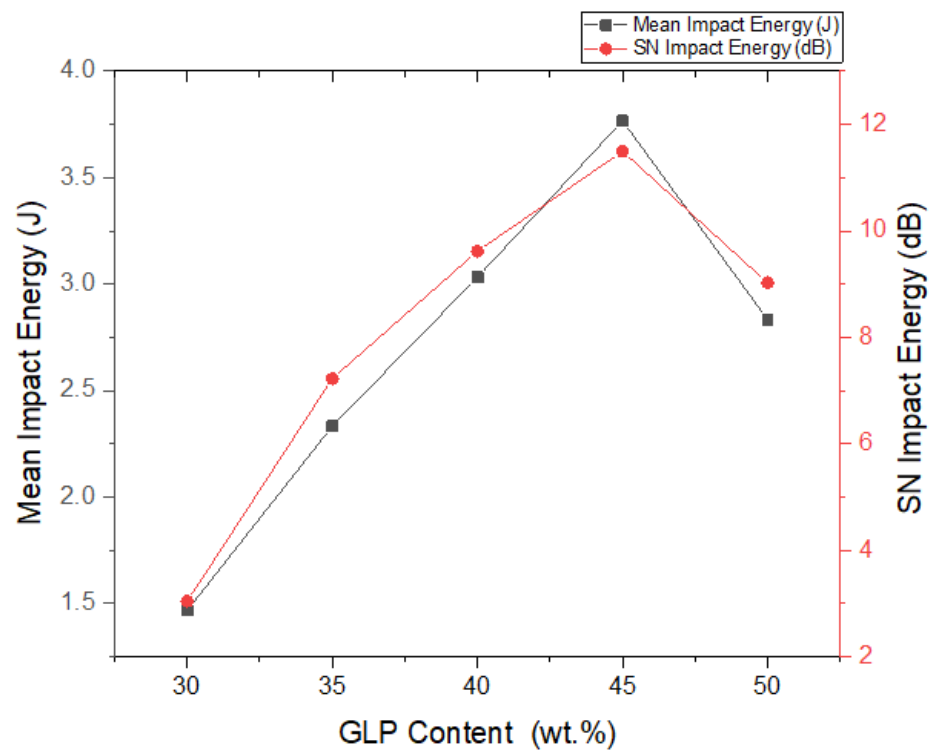

\section{Figure 4}

(A) Variation of Impact Energy Mean and S/N ratio with Particle Size

(B) Variation of Impact Energy Mean and S/N ratio with GLP Content 

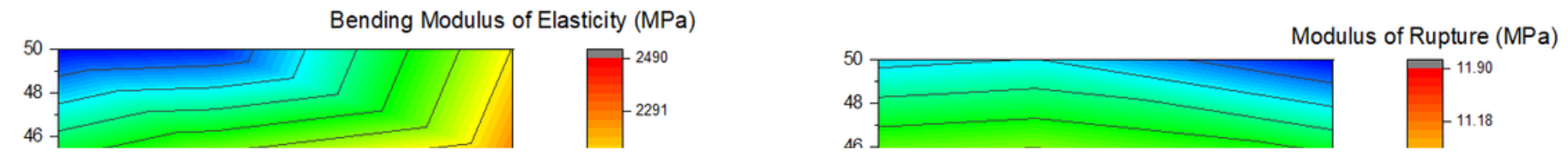

\section{Figure 5}

(A) Interaction of Particle Size with Particle Content on the Modulus of Elasticity of GLP-HDPE Composite Material

(B) Interaction of Particle Size with Particle Content on the Modulus of Rupture of GLP-HDPE Composite Material

(C) Interaction of Particle Size with Particle Content on Impact Energy of GLP-HDPE Composite Material

\section{Figure 6}
A: Predicted and experimental Bending Modulus of Elasticity of GLP-HDPE composites
B: Predicted and experimental Modulus of Rupture of GLP-HDPE composites
C: Predicted and experimental Impact Energy of GLP-HDPE composites 